\title{
Risk Factors for Glaucoma Needing More Attention
}

\author{
Anne L. Coleman ${ }^{*}, 1,2$ and Gergana Kodjebacheva ${ }^{1,3}$ \\ ${ }^{1}$ Jules Stein Eye Institute and the Department of Ophthalmology, David Geffen School of Medicine at University of \\ California, Los Angeles, (UCLA), USA \\ ${ }^{2}$ Department of Epidemiology, School of Public Health, UCLA, USA \\ ${ }^{3}$ Department of Community Health Sciences, School of Public Health, UCLA, USA
}

\begin{abstract}
Glaucoma is defined as a chronic progressive optic neuropathy, for which elevated intraocular pressure (IOP) is the only modifiable risk factor. Emerging research indicates that modifiable factors besides IOP may be associated with the presence of glaucoma. In this review, we discuss the role of modifiable determinants, specifically socioeconomic status, nutritional intake, body mass index and obesity, exercise, smoking, and sleep apnea, in the presence of glaucoma. Preliminary studies suggest that associations may exist between these non-inherent factors and glaucoma although research had significant limitations. The mechanisms of influence are unknown or understudied. Research needs to incorporate the broader behavioral and social factors that may affect glaucoma status.
\end{abstract}

\section{INTRODUCTION}

Given the detrimental effects of glaucoma [1-5], we need to understand the various factors that affect its presence. Glaucoma is a condition, for which elevated intraocular pressure (IOP), is currently the only modifiable risk factor. Demographic factors (also known as non-modifiable or inherent determinants) are related to the prevalence of glaucoma. Blacks are four to five times more likely to have glaucoma than whites [4]. The rates of primary angle closure glaucoma are higher in Asians than in Whites [6]. Women may be slightly more likely to suffer from glaucoma than men, when adjusting for age [7].

Considerable interest exists in preventive measures for the development of glaucomatous optic nerve damage and visual field loss, other than IOP lowering. Emerging research indicates that modifiable factors besides IOP may be associated with the presence of glaucoma. In this review, we discuss the role of modifiable (including behavioral and societal) characteristics in the presence of glaucoma, specifically socioeconomic status (SES), nutritional intake, body mass index (BMI) and obesity, exercise, smoking, and sleep apnea.

\section{SOCIOECONOMIC STATUS (SES)}

Research regarding the association between SES and glaucoma is scarce. Some studies have examined the relationship between SES and knowledge of or attitudes towards glaucoma. The 2005 Survey of Public Knowledge, Attitudes, and Practices Related to Eye Health and Disease, which involved 3,180 telephone interviews with randomly selected adults, aged 18 and older, found that having heard of glaucoma is associated $(\mathrm{p}<.001)$ with having insurance,

*Address correspondence to this author at the Jules Stein Eye Institute, 100 Stein Plaza, Los Angeles, California 90095-7004, USA; Tel: (310) 8255298; E-mail: coleman@jsei.ucla.edu higher annual household income, and higher education [8]. Those with higher SES, as defined by greater educational attainment, are more likely to know of glaucoma and its pathophysiology, treatment, and consequences, controlling for age, sex, and duration of glaucoma [9]. Lack of awareness about glaucoma in a general eye clinic was associated with lower educational attainment [10]. Another study investigated the association between SES and the presence of glaucoma. This case-control study of 220 glaucoma cases, recruited in the UK, found that individuals with advanced glaucoma were more likely to be of "lower occupational class," lack vehicles, and rent instead of own their houses [11].

Recently, we proposed a conceptual model to explain the visual functioning of individuals and communities [12]. In the conceptual framework, the income disparities in the prevalence of visual impairment are explained by lower access to care, and limited individual knowledge regarding eye diseases and negative attitudes towards receipt of eye care among various groups [12]. African Americans, who may have lower access to health care, are less likely to undergo glaucoma surgery [13]. Treatment for glaucoma was problematic in African American beneficiaries due to lower access to care in one study [14].

Prior research found that SES primarily explained racial/ethnic disparities in functioning once individuals had chronic diseases; SES moderately explained differences in disease prevalence [15]. Therefore, SES may especially contribute to our understanding in disparities among individuals with late glaucoma since the lack of timely identification and treatment for glaucoma in individuals with low SES may result in the economic differences in the presence of the disease.

Research regarding the relationship between glaucoma and SES used different definitions of SES. Some studies only investigated the influence of SES on knowledge 
regarding glaucoma instead of glaucoma presence. SES may interact with other factors, such as race/ethnicity, family history of glaucoma, and time since last visit to an ophthalmologist. Unfamiliarity with glaucoma has been associated with being African American and Latino [10]. The relationship between SES and glaucoma has been explained by recall of family history of glaucoma and time since last visit to ophthalmologist [11]. Research needs to assess the importance of other factors, such as demographics and health care utilization patterns, when examining the influence of SES.

\section{NUTRITIONAL INTAKE}

\section{Intake of Antioxidants}

Reactive oxygen species (ROS) are related to the pathogenesis of primary open angle glaucoma. Oxidative DNA damage in the ocular epithelium that regulates the trabecular meshwork is more severe in glaucoma patients compared to controls [16]. Theoretically, oxidative stress is related to the neuronal cell death affecting the optic nerve [17].

Two large studies investigated the relationship between the intake of antioxidants and glaucoma. In the Nurses' Health Study and Health Professionals Follow-up Study, there were 474 self-reported, confirmed glaucoma cases. The mean age of females was 48 years and that of males was 54 years. Using the Block food frequency questionnaires to assess dietary intake, investigators found no strong associations between primary open-angle glaucoma (POAG) diagnosis and the consumption of citrus foods, cruciferous vegetables, yellow vegetables, green leafy vegetables, all fruits combined, and all vegetables combined, and Vitamins $\mathrm{A}$ and $\mathrm{C}$, and alpha- and beta-carotenes. There was a $33 \%$ decreased risk of POAG in the highest quintile of Vitamin $\mathrm{E}$ intake compared to the lowest $(\mathrm{RR}=0.67,95 \% \mathrm{CI}$ : 0.50 , 0.90) [18]. In the multi-center Study of Osteoporotic Fractures including 1,155 women, we found that women who consumed at least one serving per month of green collards and kale, more than two servings per week of carrots per week, and at least one serving per week of canned or dried peaches, had a decreased likelihood of having glaucoma. In addition, a suggestive relationship existed between the greater intake of Vitamins B2 and A, obtained from natural food sources, and the decreased likelihood of glaucoma. The intake of dietary vitamin $\mathrm{C}$ increased the likelihood of having glaucoma [19]. These two studies presented preliminary evidence that there may be a relationship between nutritional intake and the presence of glaucoma.

\section{Intake of Fats}

Dietary fatty acids may influence the concentration of endogenous PG-F2 $\alpha$. Safflower oil supplementation was associated with a $13 \%$ decrease in IOP in rats at 40 weeks compared to safflower, flaxseed, and tuna oil supplementation [20]. Safflower, corn, and sunflower oils or meat contain N-6 polyunsaturated fatty acids (PUFAs). Flaxseed, canola and soy oils, leavy green vegetables, or fish oil, contain N-3 PUFAs.

The Nurses' Health Study and Health Professionals Follow-up Study involving the same 474 self-reported glaucoma cases above, found no relationship between the intake of major fats and POAG [21]. High-tension glaucoma was more likely in individuals consuming a higher ratio of $\mathrm{n}-$ 3 to $n-6$ polyunsaturated fat.

Studies regarding dietary and fat intake relied on selfreport of dietary consumption, which is subject to the recall bias. The Nurses' Health and Health Professionals Follow-up Study that investigated the role of the intake of fats and antioxidants, used self-reported glaucoma to identify individuals with the condition; the study did confirm the glaucoma cases. The Study of Osteoporotic Fractures, which found associations with the intake of fruits, vegetables and dietary antioxidants, included a relatively healthy cohort of older women and the results could not be generalized to males and less healthy females.

It is unknown why certain fruits/vegetables and antioxidants may be related to glaucoma, whether other constituents of fruits and vegetables besides antioxidants may be important, what the optimal dietary intake that decreases the prevalence of glaucoma may be, and what confounding factors play a role. Results regarding associations with dietary intake may be confounded by lifestyle factors. It is further unclear whether some antioxidants may do harm since the Study of Osteoporotic Fractures found that higher consumption of Vitamin $\mathrm{C}$ was related to a higher prevalence of glaucoma. Despite the limitations and unknowns related to the research regarding nutritional intake, the diet of individuals seems to affect glaucoma status. The associations should not be surprising since nutritional factors affect eye health [22].

\section{Body Mass Index (BMI) and Obesity}

Body mass index (BMI) and obesity which are also associated with nutritional intake, might be related to glaucoma status. Obesity may increase blood viscosity and episcleral venous pressure, and damage aqueous outflow facility [23-26]. Ocular hypertension is further related to hypertension [27-30], diabetes [31], and insulin resistance [31-33], which have been linked to obesity. A few studies examined the relationship of IOP or ocular hypertension to BMI or obesity. In the Beaver Dam Eye Study, having higher IOP was associated with higher BMI [34]. In another study, ocular hypertension and BMI of 30 or greater were related, when controlling for age and sex [35]. A study of 25,216 Japanese adolescents and adults aged 14-94, reporting both cross-sectional and longitudinal results; found that higher BMI was associated with elevated IOP, regardless of age, sex, and blood pressure [36]. Some studies suggest that the association between obesity and ocular hypertension may reflect an underlying association between insulin resistance and ocular hypertension since the association between obesity measures and IOP was not significant after adjustments for glucose and other confounders [31]. The relationship between obesity measures and IOP dissipated after adjusting for glucose in another study [31].

Other studies investigated a potential link between the presence of open-angle glaucoma and BMI or obesity. In the Barbados Eye Study, higher BMI tended to decrease the likelihood of open-angle glaucoma presence, after adjusting for age [37]. In contrast, another study found that higher 
BMI was related to a greater likelihood of clinical diagnosis of glaucoma among individuals admitted to a hospital. The researchers only reviewed medical records to obtain the information for this study [38]. In another study of 288 control subjects and 186 glaucoma patients in Switzerland, individuals with glaucoma tended to have lower BMI than those without the condition [39]. In a case-control study, there was no difference in BMI status in individuals with and without glaucoma [39]. A recent literature review concluded that while evidence exists regarding the association between higher IOP and obesity (as defined by higher BMI), findings regarding the relationship between glaucomatous optic neuropathy and obesity are conflicting [40]. It is unclear whether higher BMI may increase or decrease the likelihood of having glaucoma and what confounding factors play a role.

\section{Exercise}

Obesity is related to exercise; exercise has been related to glaucoma presence. Exercise may alter episcleral venous pressure [41], increase blood lactate and decreases blood ph [42], change plasma osmolarity by increasing serum osmolarity [43], and increase the facility of eye channels outflow stopping obstruction of the aqueous outflow pathways [44]. Exercise temporarily reduced IOP in individuals without glaucoma [45] and with glaucoma [45, 46]. The variations in the percentage reduction in IOP may be due to duration and type of exercise, timing of IOP assessment, demographic characteristics, and seasonal differences [45]. In one study that included 7 subjects with and 7 subjects without glaucoma, the IOP in all subjects dropped between 56 and $61 \%$, following five minutes of walking and jogging [45]. The effect of exercise may dissipate once subjects stop exercising. In a study of 9 sedentary glaucoma suspects who underwent 3 months of aerobic training, IOP levels returned to their original measurements three weeks after exercise cessation [46].

Overall, exercise seems to have a beneficial effect on IOP. Studies regarding the benefits of exercise, however, included small non-probability samples of subjects. It is arguable what the optimal level, type, and duration of exercise may be, whether the initial level of fitness and degree of exhaustion make a difference, what the benefits of exercise in sedentary subjects and older adults may be, and if a combined effect of exercise and intake of glaucoma medications exists.

\section{Smoking}

Cigarette smoking increases the risk of vascular disease [47]. Primary open angle glaucoma interferes with the blood flow to the optic nerve head and thus may have a vascular origin [48]. A case-control study found that current cigarette smoking was related to glaucoma presence in multiple logistic regression analysis [49]. Other studies failed to find an association between smoking and glaucoma. Specifically, smoking was not related to open-angle glaucoma in a population-based cross-sectional study of Hispanics aged older than 40 years residing in Arizona [50]. Previous or current smoking was not associated with the presence of glaucoma in the population-based study conducted in Beaver Dam, Wisconsin, in individuals ages 43 to 84 [51]. In two case-control studies, one conducted in Congo [52], and another in France [53], researchers found smoking was not related to glaucoma status. In a recent meta-analysis of existing studies, an association existed between having primary open-angle glaucoma and current smoking; no relationship with former smoking was present [54]. Smoking status has a strong association with eye health, especially age-related macular degeneration [55], but population-based studies found no association in the area of glaucoma.

\section{Sleep Apnea}

The sleep apnea syndrome (OSAS) is described as the repetitive, complete, or partial collapse of the pharyngeal airway during sleep [56]. Each episode (lasting 10 seconds to 1 minute) is terminated by arousal that causes sleep disturbance [57]. OSAS is associated with daytime sleep problems including sleepiness, chronic fatigue, and compromised cognitive function. Potential risk factors for sleep apnea include obesity, being a male, alcohol use, smoking, and snoring [58, 59]. OSAS may result in abnormal blood coagulation, systemic hypertension, cerebrovascular disease, vasospastic disease, and optic nerve vascular dysregulation [60]. In 212 patients in an eye clinic, there was an association between open-angle glaucoma and sleep-disturbed breathing, which was assessed by a questionnaire [61]. In 114 patients evaluated for OSAS, 7\% of patients with OSAS had open-angle glaucoma, which was higher than that expected in the general population [62]. In 51 subjects with OSAS, there was a higher likelihood of normal-tension glaucoma compared to normal white controls of the same age [60]. The prevalence of OAG in 228 patients with OSAS, however, was $2 \%$, which is similar to the rate of $1.5-3 \%$ in the general population [63].

One limitation of existing studies is the use of subjective information to determine the presence of sleep apnea. A study with a larger sample size $(n=212)$ that found an association between open angle glaucoma and sleepdisturbed breathing (SDB), assessed SDB by a questionnaire instead of objective measurement [61]. The reciprocal relationship between sleep apnea and glaucoma is not clear. In addition, as with other potential modifiable risk factors, it is unknown what the influence of sleep apnea is in the prevalence, incidence, and development of the disease.

\section{CONCLUSION}

Although current research tentatively supports that modifiable factors other than IOP may be related to the presence of glaucoma, these studies have significant limitations. Few case-control or population-based studies investigated the associations. Promising areas for future case-control studies are related to the role of nutritional factors, exercise, and sleep apnea.

Individuals with low SES are involved in more unhealthy behaviors and may be more likely to be members of minority groups [64]. They consume less fruits and vegetables, are more likely to be obese, have less time to exercise [65], and are more likely to smoke [15]. In the broader context, since differences in knowledge about glaucoma are greatest between individuals with low and high SES but not as significant in people within middle and high groups of SES [9], steps to decrease socioeconomic inequalities are essential. SES is a societal issue and ophthalmologists have a 
limited ability to interfere. If we hope to decrease the burden of glaucoma, future research needs to incorporate the broader behavioral and social factors that may affect glaucoma.

\section{REFERENCES}

[1] Quigley HA. Number of people with glaucoma worldwide. $\mathrm{Br} \mathrm{J}$ Ophthalmol 1996; 80: 389-93.

[2] Tielsch JM, Sommer A, Katz J, Royall RM, Quigley HA, Javitt J. Racial variations in the prevalence of primary open-angle glaucoma. The Baltimore eye survey. JAMA 1991; 266: 369-74.

[3] Resnikoff S, Pascolini D, Etya'ale D, et al. Global data on visual impairment in the year 2002. Bull World Health Organ 2004; 82: $844-51$.

[4] Tielsch JM, Sommer A, Katz J, Quigley H, Ezrine S. Socioeconomic status and visual impairment among urban Americans. Arch Ophthalmol 1991; 109: 637-41.

[5] Coleman AL, Cummings SR, Yu F, et al. Binocular visual-field loss increases the risk of future falls in older white women. J Am Geriatr Soc 2007; 55 : 357-64.

[6] Law SK. Asian Americans: glaucoma. Int Ophthalmol Clin 2003; 43: 133-49.

[7] Mitchell P, Smith W, Attebo K, Healey PR. Prevalence of openangle glaucoma in Australia. The Blue Mountains eye study. Ophthalmology 1996; 103: 1661-9.

[8] National Eye Institute (NEI) and the Lions Clubs International Foundation (LCIF). 2005 Survey of Public Knowledge, Attitudes, and Practices Related to Eye Health and Disease. Final report. 22 February 2008 Available from: http://www.nei.nih.gov/kap/2005 KAPFinalRpt.pdf

[9] Hoevenaars JGMM, Schouten JSAG, Borne BVD, Beckers HJM, Webers CAB. Socioeconomic differences in glaucoma patients' knowledge, need for information and expectations of treatments. Acta Ophthalmol Scand 2006; 84: 84-91.

[10] Gasch AT, Wang P, Pasquale LR. Determinants of glaucoma awareness in a general eye clinic. Ophthalmology 2000; 107: 3038.

[11] Fraser S, Bunce C, Wormald R, Brunner E. Deprivation and late presentation of glaucoma: case-control study. BMJ 2001; 322: 63943.

[12] Coleman AL, Kodjebacheva G, Wallace SP, et al. Visual functioning of individuals and communities: a conceptual framework. Clin Med Geriatr 2008; 2: 13-20.

[13] Devgan U, Yu F, Kim E, Coleman AL. Surgical undertreatment of glaucoma in black beneficiaries of Medicare. Arch Ophthalmol 2000; 118: 253-6.

[14] Wang F, Javitt JC, Tielsch JM. Racial variations in treatment for glaucoma and cataract among Medicare recipients. Ophthalmic Epidemiol 1997; 4: 89-100.

[15] Kington RS, Smith JP. Socioeconomic status and racial and ethnic differences in functional status associated with chronic diseases. Aust J Polit Hist 1997; 5: 805-10.

[16] Claudio Sacca SC, Pascotto A, Camicione P, Capris P, Izzotti A. Oxidative DNA damage in the human trabecular meshwork: clinical correlation in patients with primary open-angle glaucoma. Arch Ophthalmol 2005; 123: 458-63.

[17] Izzotti A, Saccà SC, Cartiglia C, De Flora, S. Oxidative deoxyribonucleic acid damage in the eyes of glaucoma patients. Am J Med 2003; 114: 638-46.

[18] Kang JH, Pasquale LR, Willett W, et al. Antioxidant intake and primary open-angle glaucoma: a prospective study. Am J Epidemiol 2003; 158: 337-46.

[19] Coleman AL, Stone KL, Kodjebacheva G, et al. Glaucoma Risk and the Consumption of Fruits and Vegetables Among Older Women in the Study of Osteoporotic Fractures. AJO 2008; 145: 1081-89.

[20] Nguyen CTO, Bui BV, Sinclair AJ, Vingrys AJ. Dietary omega 3 fatty acids decrease intraocular pressure with age by increasing aqueous outflow. IOVS 2007; 48: 756-62.

[21] Kang JH, Pasquale LR, Willett WC, et al. Dietary fat consumption and primary open-angle glaucoma. Am J Clin Nutr 2004; 79: 75564.

[22] Congdon NG, West KP. Nutrition and the eye. Ocular manifestations of systemic disease. Curr Opin Opthalmol 1999; 10: 464-73.
[23] Bulpitt CJ, Hodes C, Everitt MG. Intraocular pressure and systemic blood pressure in the elderly. Br J Ophthalmol 1975; 59: 717-20.

[24] Savinova OV, Sugiyama F, Marti JE, et al. Intraocular pressure in genetically distinct mice: an update and strain survey. BMC Genet 2001; 2: 12 .

[25] Shiose Y. The aging effect on intraocular pressure in an apparently normal population. Arch Ophthalmol 1984; 102: 883-7.

[26] Shiose Y, Kawase Y. A new approach to stratified normal intraocular pressure in a general population. Am J Ophthalmol 1986; 101: 714-21.

[27] Bonomi L, Marchini G, Marraffa M, et al. Vascular risk factors for primary open angle glaucoma: the Egna-Neumarkt Study. Ophthalmol 2000; 107: 1287-93.

[28] Dielemans I, Vingerling JR, Algra D, Hofman A, Grobbee DE, de Jong PT. Primary open-angle glaucoma, intraocular pressure, and systemic blood pressure in the general elderly population. The rotterdam study. Ophthalmology 1995; 102: 54-60.

[29] Klein BE, Klein R, Intraocular pressure and cardiovascular risk variables. Arch Ophthalmol 1981; 99: 837-9.

[30] Leske MC, Podgor MJ. Intraocular pressure, cardiovascular risk variables, and visual field defects. Am J Epidemiol 1983: 118: 2807.

[31] Oh SW, Lee S, Park C, Kim DJ. Elevated intraocular pressure is associated with insulin resistance and metabolic syndrome. Diabetes Metab Res Rev 2005; 21: 434-40.

[32] Nakamura M, Ishimitsu $T$, Matsuoka $H$, Ohrui M, Hisauchi $T$. Implications of obesity for target organ injuries and cardiovascular risk factors in hypertensive subjects. Nippon Jinzo Gakkai Shi 1997; 39: 746-52.

[33] Wu SY, Leske MC. Associations with intraocular pressure in the Barbados eye study. Arch Ophthalmol 1997; 115: 1572-6.

[34] Klein BE, Klein R, Linton KL. Intraocular pressure in an American community. The Beaver Dam eye study. Invest Ophthalmol Vis Sci 1992; 33: 2224-8.

[35] Jaén Díaz J, Sanz Alcolea I, López De Castro F, et al. Glaucoma and ocular hypertension in primary care. Aten Primaria 2001; 28 : 23-30.

[36] Mori K, Ando F, Nomura H, Sato Y, Shimokata H. Relationship between intraocular pressure and obesity in Japan. Int J Epidemiol 2000; 29: 661-6.

[37] Leske MC, Connell AM, Wu SY, Hyman LG, Schachat AP. Risk factors for open-angle glaucoma. The Barbados Eye Study. Arch Ophthalmol 1995; 113: 918-24.

[38] Zang EA, Wynder EL. The association between body mass index and the relative frequencies of diseases in a sample of hospitalized patients. Nutr Cancer 1994; 21: 247-61.

[39] Gasser P, Stümpfig D, Schötzau A, Ackermann-Liebrich U, Flammer J. Body mass index in glaucoma. J Glaucoma 1999; 8: 811

[40] Cheung N, Wong TY. Obesity and Eye Diseases. Surv Ophthalmol 2007; 52: 180-95.

[41] Podos S, Minas T, Moor F. A new instrument to measure episcleral venous pressure. Arch Ophthalmol 1968; 80: 209-11.

[42] Marcus DF, Krupin T, Podos SM, Becker B. The effect of exercise on intraocular pressure. I. Human beings. Invest Ophthalmol 1970; 9: 749-52.

[43] Galin MA, Davison R, Pasmanik S. An osmotic comparison of urea and mannitol. Am J Opthalmol 1963; 55: 244-7.

[44] Pandolh M, Kwaan HC. Fibrinolysis in the anterior segment of the eye. Arch Ophthalmol 1967; 77: 99-104.

[45] Qureshi IA. The effects of mild, moderate, and severe exercise on intraocular pressure in glaucoma patients. Jpn J Physiol 1995; 45: 561-9.

[46] Passo MS, Goldberg L, Elliot DL, Van Buskirk EM. Exercise training reduces intraocular pressure among subjects suspected of having glaucoma. Arch Ophthalmol 1991; 109: 1096-8.

[47] Holbrook JH. Diseases due to environmental hazards. In Isselbacher KJ, Adams RD, Braunwald E, Petersdorf RG, Wilson JD, Eds. Harrison's principles of internal medicine. $9^{\text {th }}$ ed. New York: McGraw Hill 1980; pp. 938-41.

[48] Shields MB. Textbook of Glaucoma. Baltimore, MD: Williams \& Wilkins 1982: pp. 95-8.

[49] Wilson MR, Hertzmark E, Walker AM, Childs-Shaw K, Epstein DL. A case-control study of risk factors in open angle glaucoma. Arch Ophthalmol 1987; 105: 1066-71. 
[50] Quigley HA, West SK, Rodriguez J, Munoz B, Klein R, Snyder R. The prevalence of glaucoma in a population-based study of Hispanic subjects: proyecto VER. Arch Ophthalmol 2001; 119: 1819-26.

[51] Klein BE, Klein R, Ritter LL. Relationship of drinking alcohol and smoking to prevalence of open-angle glaucoma. The Beaver Dam eye study. Ophthalmology 1993; 100: 1609-13.

[52] Kaimbo DK, Buntinx F, Missotten L. Risk factors for open-angle glaucoma: a case-control study. J Clin Epidemiol 2001; 54: 166-71.

[53] Charliat G, Jolly D, Blanchard F, Genetic risk factor in primary open-angle glaucoma: a case-control study. Ophthalmic Epidemiol 1994; 1: 131-8.

[54] Bonovas S, Filioussi K, Tsantes A, Peponis V. Epidemiological association between cigarette smoking and primary open-angle glaucoma: a meta-analysis. Public Health 2004; 118: 256-61.

[55] Thornton J, Edwards R, Mitchell P, Harrison RA, Buchan I, Kelly SP. Smoking and age-related macular degeneration: a review of association. Eye 2005; 19: 935-44.

[56] Bassiri A, Guilleminault C. Clinical features and evaluation of obstructive sleep apnea-hypopnea syndrome. In: Kryger MH, Roth T, Dement W, Eds. Principles and practice of sleep medicine. Philadelphia: Saunders, 2000; pp. 869-93.

[57] Malhotra D, White DP. Obstructive sleep apnoea. Lancet 2002; 360: $237-45$
[58] Young T, Skatrud J, Peppard PE. Risk Factors for obstructive sleep apnea in adults. JAMA 2004; 291: 2013-6.

[59] Issa FG, Sullivan CE. Alcohol, snoring and sleep apnea. J Neurol Neurosurg Psychiatry 1982; 45: 353-9.

[60] Sergi M, Salerno DE, Rizzi M, et al. Prevalence of normal tension glaucoma in obstructive sleep apnea syndrome patients. J Glaucoma 2007; 16: 42-6.

[61] Onen HS, Mouriaux F, Berramdane L, Dascotte JC, Kulik JF, Rouland JF. High prevalence of sleep-disordered breathing in patients with primary open-angle glaucoma. Acta Ophthalmol Scand 2000; 78: 638-41

[62] Mojon DS, Hess CW, Goldblum D, et al. High prevalence of glaucoma in patients with sleep apnea syndrome. Ophthalmol 1999; 106: 1009-12.

[63] Geyer O, Cohen N, Segev E, et al. The prevalence of glaucoma in patients with sleep apnea syndrome: same as in the general population. Am J Ophthalmol 2003; 136: 1093-6.

[64] Williams DR. Race, socioeconomic status, and health. The added effects of racism and discrimination. Ann NY Acad Sci 1999; 896: 173-88.

[65] Lynch JW, Kaplan GA, Salonen JT. Why do poor people behave poorly? Variation in adult health behaviours and psychosocial characteristics by stages of the socioeconomic lifecourse. Soc Sci Med 1997; 44: 6809-19.

(C) Coleman and Kodjebacheva; Licensee Bentham Open.

This is an open access article licensed under the terms of the Creative Commons Attribution Non-Commercial License (http: //creativecommons.org/licenses/by$\mathrm{nc} / 3.0 /$ ) which permits unrestricted, non-commercial use, distribution and reproduction in any medium, provided the work is properly cited. 